\title{
Employee Retention: Role of Communication Satisfaction, Procedural of Justice, And Organizational Citizenship Behaviors in A Private Higher Learning Institution in Malaysia
}

\author{
Erni Tanius \\ University Selangor
}

Employee retention (ER) has become the primary concern of organizations regardless of any industry and countries. The prosperous and the sustainability of the organization very much depend on the ability to retain their talented employees. Hence, this study attempts to understand the role of communication satisfaction (CS), procedural justice (PJ), and organizational citizenship behaviors (OCB) in employee retention. Furthermore, the study would like to identify if ER relates to the dependent variables. 195 academicians in a private university in Selangor, Malaysia joined in this survey. The variables in the questionnaire adapted from previous related studies and simple random sampling used to select respondent.

Meanwhile, the Structural Equation Modelling using a Partial Least Squares (PLS) approach uses as the method of analyzing data. Furthermore, a bootstrapping procedure with 1000 resamples was run to generate the t-values in order to estimate the structural model. The result indicated that CS and PJ influence ER and the bootstrapping analysis showed that there is an indirect effect between CS and ER as well as between PJ and ER. Thus the study recommended that employers must support and practice CS and PJ in the work environment. As a result, the relationship becomes closer and subsequently reduces the likelihood of employees to leave the organization.

Keywords: Employee retention, Communication satisfaction, Procedural justice, Organizational citizenship behaviors, Private higher learning institution, Malaysia 